\title{
Prospects of Nanostructure Materials and Their Composites as Antimicrobial Agents
}

\author{
Anupriya Baranwal ${ }^{1}$, Ananya Srivastava ${ }^{2}$, Pradeep Kumar ${ }^{3 *}$, Vivek K. Bajpai ${ }^{4}$, \\ Pawan K. Maurya ${ }^{5}$ and Pranjal Chandra ${ }^{1 *}$
}

${ }^{1}$ Department of Biosciences and Bioengineering, Indian Institute of Technology Guwahati, Guwahati, India, ${ }^{2}$ Department of Pharmacology and Toxicology, National Institute of Pharmaceutical Education and Research, Guwahati, India, ${ }^{3}$ Department of Forestry, North Eastern Regional Institute of Science and Technology, Deemed University, Nirjuli, India, ${ }^{4}$ Department of Energy and Materials Engineering, Dongguk University-Seoul, Seoul, South Korea, ${ }^{5}$ Interdisciplinary Laboratory of Clinical Neuroscience (LiNC), Department of Psychiatry, Universidade Federal de São Paulo-UNIFESP, São Paulo, Brazil

\section{OPEN ACCESS}

Edited by:

Arunas Ramanavicius,

Vilnius University, Lithuania

Reviewed by:

Umme Thahira Khatoon,

National Institute of Technology

Warangal, India

M. Oves,

King Abdulaziz University, Saudi Arabia

*Correspondence:

Pradeep Kumar

pkbiotech@gmail.com

Pranjal Chandra

pchandra13@iitg.ernet.in;

pranjalmicro13@gmail.com

Specialty section:

This article was submitted to

Antimicrobials, Resistance and

Chemotherapy,

a section of the journal

Frontiers in Microbiology

Received: 10 September 2017

Accepted: 22 February 2018

Published: 09 March 2018

Citation:

Baranwal A, Srivastava A, Kumar $P$,

Bajpai VK, Maurya PK and Chandra P

(2018) Prospects of Nanostructure

Materials and Their Composites as

Antimicrobial Agents.

Front. Microbiol. 9:422.

doi: 10.3389/fmicb.2018.00422
Nanostructured materials (NSMs) have increasingly been used as a substitute for antibiotics and additives in various products to impart microbicidal effect. In particular, use of silver nanoparticles (AgNPs) has garnered huge researchers' attention as potent bactericidal agent due to the inherent antimicrobial property of the silver metal. Moreover, other nanomaterials (carbon nanotubes, fullerenes, graphene, chitosan, etc.) have also been studied for their antimicrobial effects in order ensure their application in widespread domains. The present review exclusively emphasizes on materials that possess antimicrobial activity in nanoscale range and describes their various modes of antimicrobial action. It also entails broad classification of NSMs along with their application in various fields. For instance, use of AgNPs in consumer products, gold nanoparticles (AuNPs) in drug delivery. Likewise, use of zinc oxide nanoparticles (ZnO-NPs) and titanium dioxide nanoparticles $\left(\mathrm{TiO}_{2}-\mathrm{NPs}\right)$ as additives in consumer merchandises and nanoscale chitosan $(\mathrm{NCH})$ in medical products and wastewater treatment. Furthermore, this review briefly discusses the current scenario of antimicrobial nanostructured materials (aNSMs), limitations of current research and their future prospects. To put various perceptive insights on the recent advancements of such antimicrobials, an extended table is incorporated, which describes effect of NSMs of different dimensions on test microorganisms along with their potential widespread applications.

Keywords: nanostructured material, antimicrobial activity, cytotoxicity, human health, antimicrobial agent

\section{INTRODUCTION}

Microbial contamination even today is amongst primal causes of morbidity and mortality across the globe. According to reports, about half of the population in developing countries are infested with microbial contamination and annually more than 3 million people die because of it (Armentano et al., 2014). Despite spectacular advances in diagnostic and therapeutic strategies, microbial infections continue to affect biomedical and healthcare sectors due to the emergence of resistance against several available antibiotics (Murphy, 1994; Desselberger, 2000). Numerous factors including but not limited to human lifestyle changes, industrialization, civil wars, and microbial genome alterations have been recognized for their involvement in 
emergence or re-emergence of pathogens (Morse, 2001). Keeping this serious issue in consideration, development of better antimicrobial drugs has become highly imperative. Other than aforementioned issue, microbes are also known for deteriorating textiles, spoiling food products, contaminating surgical instruments and causing the damage to crops. The available conventional solutions to avert these problems are not sufficient enough, therefore, development of better alternatives is highly sought to secure the basic living standard of human beings.

Recent advances in nanostructure-based antimicrobial medications have unveiled novel prospects to combat drug resistance in microbes. Therefore, usage of NSM as an antimicrobial agent in both particle and composite form has gained enormous importance in recent years. Application of NSM in biomedical domain relies on a number of unique properties viz. optical, physical, chemical, thermal, electrical, etc. Some of these unique properties play a crucial role in providing medical relevance to the NSM while, the other properties enable them to have significance in other industries (Dakal et al., 2016). The pivotal characteristics that an aNSM should preferably possess are broad-spectrum effect, inexpensive, high specificity, and least or negligible susceptibility toward resistance development (Beyth et al., 2015). Both inorganic and organic NSMs have shown antimicrobial effects over a wide range of microbial strains (Dastjerdi and Montazer, 2010; Li et al., 2011; Latif et al., 2015), paving way for their potential applications in textile industry (Dastjerdi and Montazer, 2010), food packaging and processing industry (Duncan, 2011), agricultural products and crop safety (Khot et al., 2012), water treatment (Li et al., 2008), and construction industry (Lee et al., 2010) to prevent damages associated with microbial growth.

In this review, we have presented a broad classification of NSMs produced via. different synthetic approaches along with an overview of the nanomaterials which possess antimicrobial activity. Though, it is practically impossible to present a comprehensive overview on all NSMs including their method of synthesis, characterization techniques, and mode of antimicrobial activity in this review. However, we have tried to present a report which clearly heralds the current scenario of application of aNSMs in widespread domains along with inadequacies of current research and future prospects of NSMs as antimicrobial agents.

\section{CLASSIFICATION OF NANOSTRUCTURED MATERIALS}

A wide variety of materials exist today that is colloquially considered as NSMs, but the term NSM validates only those materials which belong to $1-100 \mathrm{~nm}$ range. NSMs may exhibit large particle size $(>100 \mathrm{~nm})$ when they combine with other materials (like polymers, biomolecules, other NSMs, etc.) to form composite NSM or when they exist in the form of aggregates (Bhushan, 2010). NSMs are broadly classified into three categories, which are further classified into different sub-categories (Figure 1i). The inorganic NSMs include nanosheets (a 2-D nanostructure whose thickness lies in the nano range), metal and metal oxide nanoparticle (particles whose diameter is usually $<100 \mathrm{~nm}$ ), nanoshells (typically, spherical nanoparticles with a dielectric core enclosed inside thin metallic shell), nanowires (wire exhibiting diameter/thickness of few nanometers), nanocrystals (material composed of atoms aligned in single- or poly-crystalline arrangement with its one dimension usually $<100 \mathrm{~nm}$ ), quantum dots (3-D nanocrystals composed of semiconducting material with their diameter lying in $2-10 \mathrm{~nm}$ range), and carbon nanotubes (cylindrical carbon nanostructures with unusual properties). Organic NSMs comprise of dendrimers (3-D, hyperbranched, tree-like polymeric nanostructures), liposomes (nano-vesicles obtained from hydration of dry phospholipids), and nano/micro capsules (material composed of natural or synthetic polymer shells in order to enclose different active materials, such as drugs, catalysts, biomolecules, etc. as its core) (Dastjerdi and Montazer, 2010).

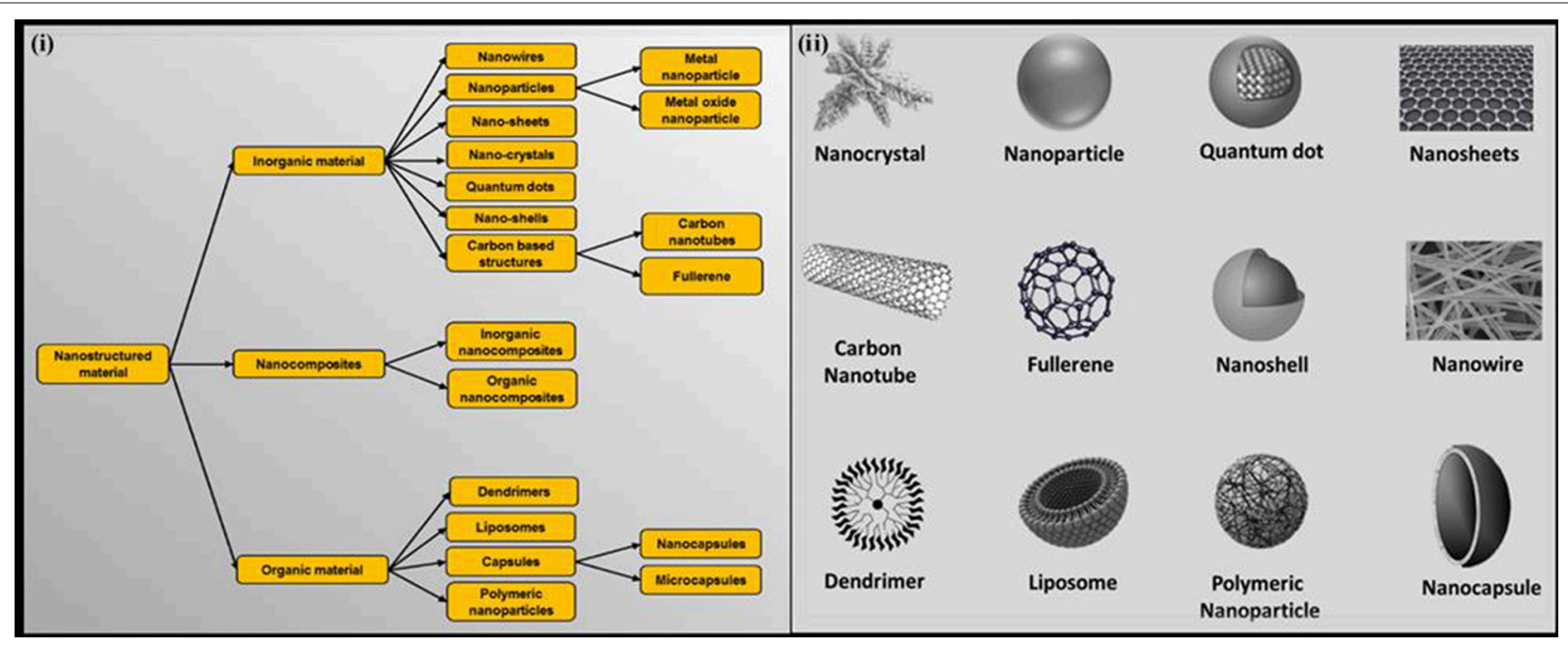

FIGURE 1 | (i) Illustration representing classification of nanostructured materials used as antimicrobials and (ii) depiction of various forms of nanostructured materials and their morphology. 
(i)

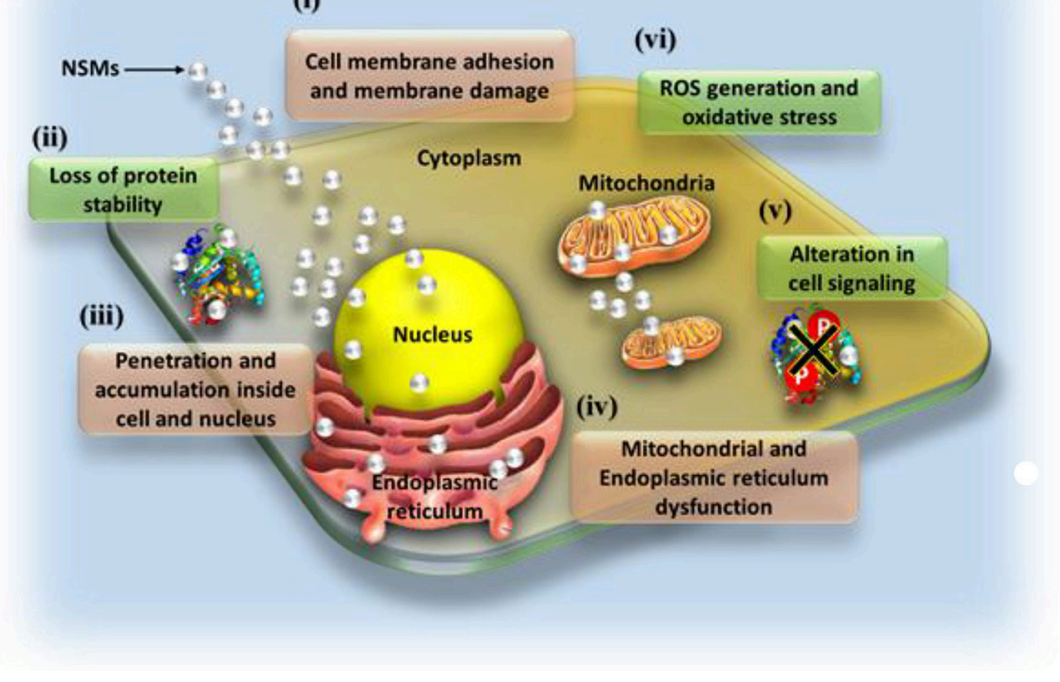

FIGURE 2 | Various modes of microbial toxicity caused by nanostructured materials.

These organic NSMs usually act as a carrier of inorganic nanoparticles and provide a wide range of biomedical applications. Figure lii shows morphological features of NSMs which exist in varied forms.

Various synthetic approaches are available today that can be employed to generate NSMs. Conventional synthetic approaches include physical and chemical processes; however, biological processes are one of the newer approaches to allow synthesis of NSMs. In certain cases, especially invasive biomedical application of NSMs, biological approaches (microbe or plant extract assisted) become a method of choice over other conventional approaches because these (biological) approaches do not elicit cellular toxicity (Ahmed et al., 2016; Baranwal et al., 2016).

\section{ANTIMICROBIAL NANOSTRUCTURED MATERIALS}

Antimicrobial effect of NSMs has been widely studied by several research groups against a wide range of microorganisms. NSMs can be regarded as the next generation antibiotics as they possess remarkable potential to overcome multidrug resistance problems in the pathogenic microbes. Depending on their ability to provide biostatic and biocidal action against microbial species, they can also be exploited in healthcare and personal care products, food safety, crop protection, water treatment, textile industries, etc. Although NSMs have shown spectacular antimicrobial effect against more than 500 microbial species, however, accurate mechanism behind their microbicidal activity is not hitherto well-understood (Beyth et al., 2015). Nonetheless, some widely accepted modes of mechanisms of antimicrobial action (Figure 2) are discussed in the following section.

\section{MECHANISMS OF MICROBIAL TOXICITY}

Electrostatic attraction between cationic NSM and anionic microbial cell membrane instigates adhesion of NSMs onto the cell wall or cell membrane which leads to cytosol shrinkage and detachment of the membrane, and eventually cell wall rupture (Dakal et al., 2016). Adhesion of NSM in some cases is followed by its penetration across the cell membrane where, it binds with biomolecules (DNA, protein, and lipids) and cause damage to them which thus, hamper crucial pathways and result in microbial cell death (Li et al., 2008). Apart from electrostatic attraction, the interaction of sulfur groups present in cell wall proteins and NSM leads to irreversible changes in the cell wall structure which subsequently disturbs the lipid bilayer integrity and increases the membrane permeability (Ghosh et al., 2012). Further modes of antimicrobial action of NSM involve the formation of reactive oxygen species (ROS) which cause increase in oxidative stress inside microbial cells. The increased levels of ROS and other free radicals result in mitochondrial and endoplasmic reticulum dysfunction and irreversible damage to biomolecules that subsequently cause genotoxic effects (Huang et al., 2008; Dizaj et al., 2014). NSMs, especially nanoparticles modulate microbial signal transduction pathways by causing de-phosphorylation of tyrosine residues on crucial proteins and thus, impart their antimicrobial effect (Dakal et al., 2016).

\section{CURRENT SCENARIO OF ANTIMICROBIAL NANOSTRUCTURED MATERIALS' APPLICATIONS}

A wide range of NSMs, such as metal and metal oxide nanoparticles, $\mathrm{NCH}$, carbon nanotubes (CNTs), organic 
nanoparticles (ONPs), etc. have found their usage in widespread domains of consumer products, food safety, agricultural products, crop protection, and industrial processes (waste water treatment, architectural/construction material, etc.). Such examples of NSMs along with their dimension analysis, antimicrobial effect on test microorganisms, and potential applications thereof has been discussed comprehensively in Table 1. This table has been complied by including reports published between year 2007 and 2018 explicitly. Though there are several reports of NSMs being used in commercial products, however, their exact nano-formulation is not disclosed anywhere, most likely due to trade-secret constraints. Some of the commercial examples of aNSM based products are nasiol ${ }^{\circledR}$ AntiMoss protection, nasiol ${ }^{\circledR}$ HomeWood protection (https:// nasiolgulf.com/), I-canNano metal paints, and I-canNano fillers (https://www.icannanopaints.com/), NanoSeal ${ }^{\mathrm{TM}}$ NanoPack (Duncan, 2011), 4Care Lenscare nano-Behälter, Acticoat Antibacterial barrier, JR Nanotech SoleFreshT nanosilver socks, and Miradent Miradent gelée toothpaste and mouth wash (Wijnhoven et al., 2010). Following section exclusively deals with applications of aNSMs in aforementioned domains.

\section{Metal/Metal Oxide Nanoparticles}

Amongst different types of metal nanoparticles (MNPs), AgNPs have witnessed their usage at much wider scale. Currently, they have been used in more than 100 consumer products for imparting antimicrobial effect, starting from storage wares, textiles, nutritional additives to kitchen appliance surface coatings, hospital consumables and wares, etc. (Li et al., 2008). The mechanism behind their microbicidal action is mostly accredited to release of $\mathrm{Ag}^{+}$ions, cell membrane or cell wall damage, disruption of electron transport and signal transduction pathway, and damage to cellular DNA and proteins due to ROS (Dakal et al., 2016; Qayyum et al., 2017). AuNPs are one of the most valuable antibacterial agents due to their biocompatibility, higher potential of functionalization, and ease of detection. The mechanism behind antibacterial effect of AuNP is not yet fully explored; however, there have been reports of bacterial damage due to modification in membrane potential, loss of ATPs (Cui et al., 2012; Abdel-Raouf et al., 2017), and ROS generation (Zheng et al., 2017). Like other MNPs, copper nanoparticles (CuNPs) have also shown excellent antimicrobial activity and changes in the morphology of microbial cell is suggested to be the plausible cause of their biocidal action (Bogdanović et al., 2014). Other examples of antimicrobial MNPs are incorporated in Table 1.

Iron oxide has long been known for its application in the biomedical sector due to its biocompatibility and magnetic property. However, analysis of antibacterial property of reduced iron $\left(\mathrm{Fe}^{0}\right)$ and iron oxide nanoparticles ( $\left.\mathrm{FeO}-\mathrm{NPs}\right)$ is relatively new. The bactericidal effect of FeO-NPs is observed either due to disruption of cell membrane, or oxidative stress inside the cell, or both (Lee et al., 2008; Arokiyaraj et al., 2013) or due to oxidation of protein and peroxidation of membrane lipids (Dinali et al., 2017). Compatibility of ZnO-NPs with human skin and their safety has made them appropriate additive for cosmetics, fabrics, and surfaces that remain in close proximity of human body (Dizaj et al., 2014). Owing to their microbicidal effect on both Gram positive and Gram negative bacteria, $\mathrm{ZnO}$ nanocomposites have been applied in food packing applications (Espitia et al., 2012). The probable mechanisms behind their antimicrobial action are the generation of ROS, the release of $\mathrm{Zn}$ ions, and the cell membrane dysfunction (Dizaj et al., 2014). Copper oxide nanoparticles (CuO-NPs) have been exploited for widespread applications, such as gas sensing, batteries, catalysis, etc. In recent past, $\mathrm{CuO}-\mathrm{NPs}$ were studied for their antimicrobial property and were reported to possess excellent bactericidal and fungicidal activity (Ren et al., 2009). Changes in surface and morphology of microbial cell are supposedly the plausible cause of their biocidal action. $\mathrm{TiO}_{2}$-NPs alone and in conjugation with non-toxic polymers exhibit spectacular antimicrobial property. Due to high refractive index and whiteness property $\mathrm{TiO}_{2}$ NPs (especially anatase form) have been used in a varied range of consumer merchandises, such as sunscreen lotions, paints, cement, coatings, and toothpaste (Weir et al., 2012). They have also been studied for their potential of potable water disinfection as they are inexpensive, significantly stable in water, nontoxic after ingestion, and result in photocatalytic disinfection ( $\mathrm{Li}$ et al., 2008). The bactericidal effect of $\mathrm{TiO}_{2}$-NPs is strongly related to the formation of ROS, particularly-OH free radicals.

\section{Fullerenes, Graphene, and Carbon Nanotubes}

Not many reports exist on the mode of antimicrobial action of fullerenes $\left(\mathrm{C}_{60}\right)$ and their derivatives thus, it would not be wise to propose their plausible applications. $\mathrm{C}_{60}$ and their certain derivatives have shown strong bactericidal activity; however, no such effect is evident in case of fullerols but they have shown virucidal activity. The antimicrobial effect of $\mathrm{C}_{60}$ and fullerol is attributed to ROS independent oxidation and formation of highly reactive singlet oxygen species, respectively. The ability of encapsulated fullerene to show antimicrobial effects in water (Lyon et al., 2006) can be used to solve waste water problems. Lately, owing to exclusive surface properties, graphene-based materials like oxides, reduced oxides (rGO), and nanocomposites have caught researchers' attention for their ability to act as antimicrobial agent (Zhu et al., 2017; Jilani et al., 2018); however, only limited number of reports are available in this regard. The mechanism behind their microbicidal activity is mostly accredited to "sheet effect" (Ocsoy et al., 2017), cell membrane dysfunction, and oxidative stress inside the cell (Liu et al., 2011). Depending on their ability to prevent microbial contamination, graphene-based materials have potential to be used in food packaging. Like other aforementioned NSMs, singlewalled nanotubes (SWNTs) have also displayed bactericidal activity against both Gram-positive and Gram-negative bacteria, but not much work has been done in this direction. The recognized mode of microbial toxicity behind SWNTs is believed to be either oxidative stress that aborts integrity of cell membrane or their adhesion onto the microbial surface (Dizaj et al., 2014). CNTs have also been used in filters and incorporated into hollow fibers to inhibit bio-fouling of surfaces and formation of biofilms (Li et al., 2008). In addition, they have also been studied for their application as construction material to impart crucial benefits 


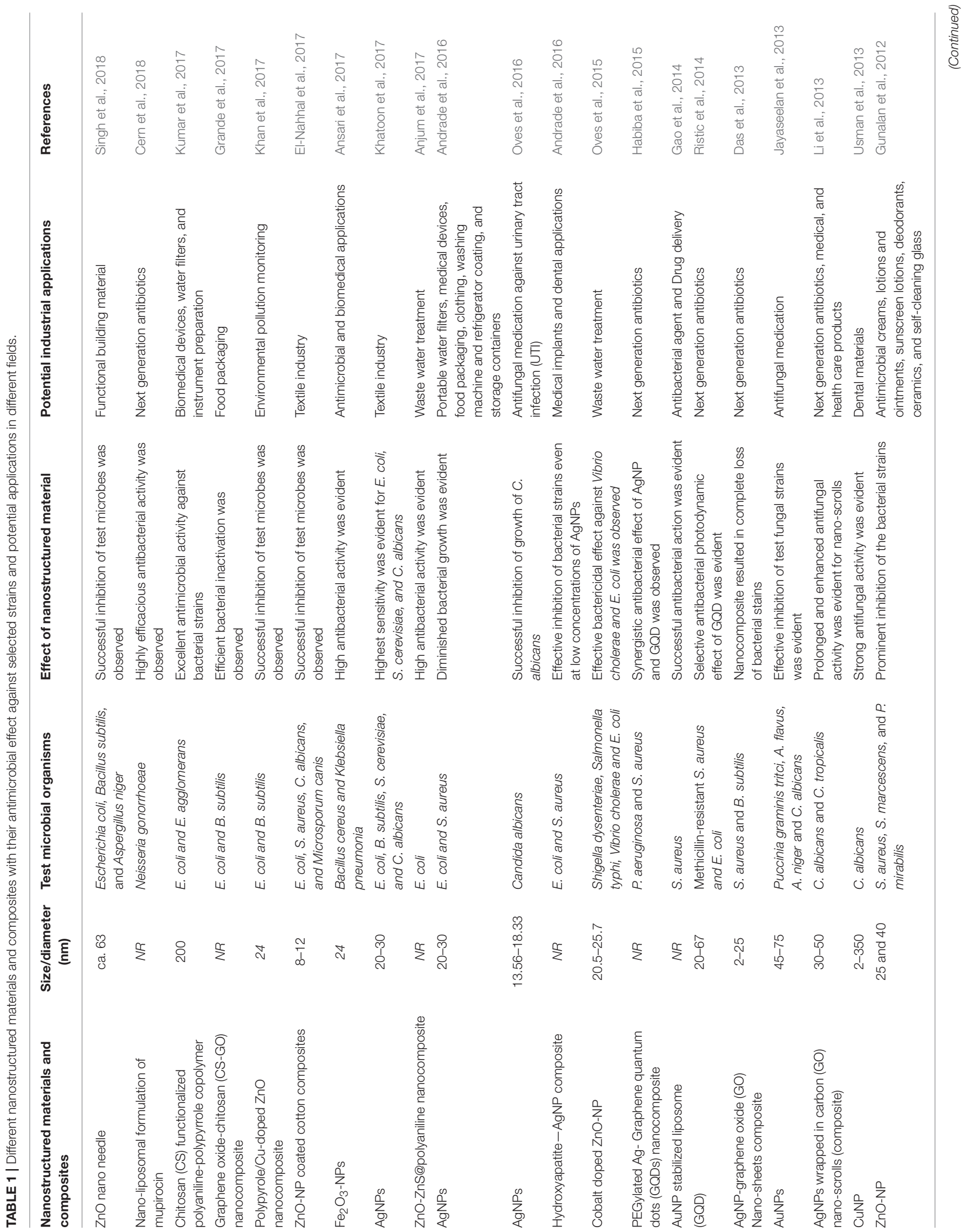



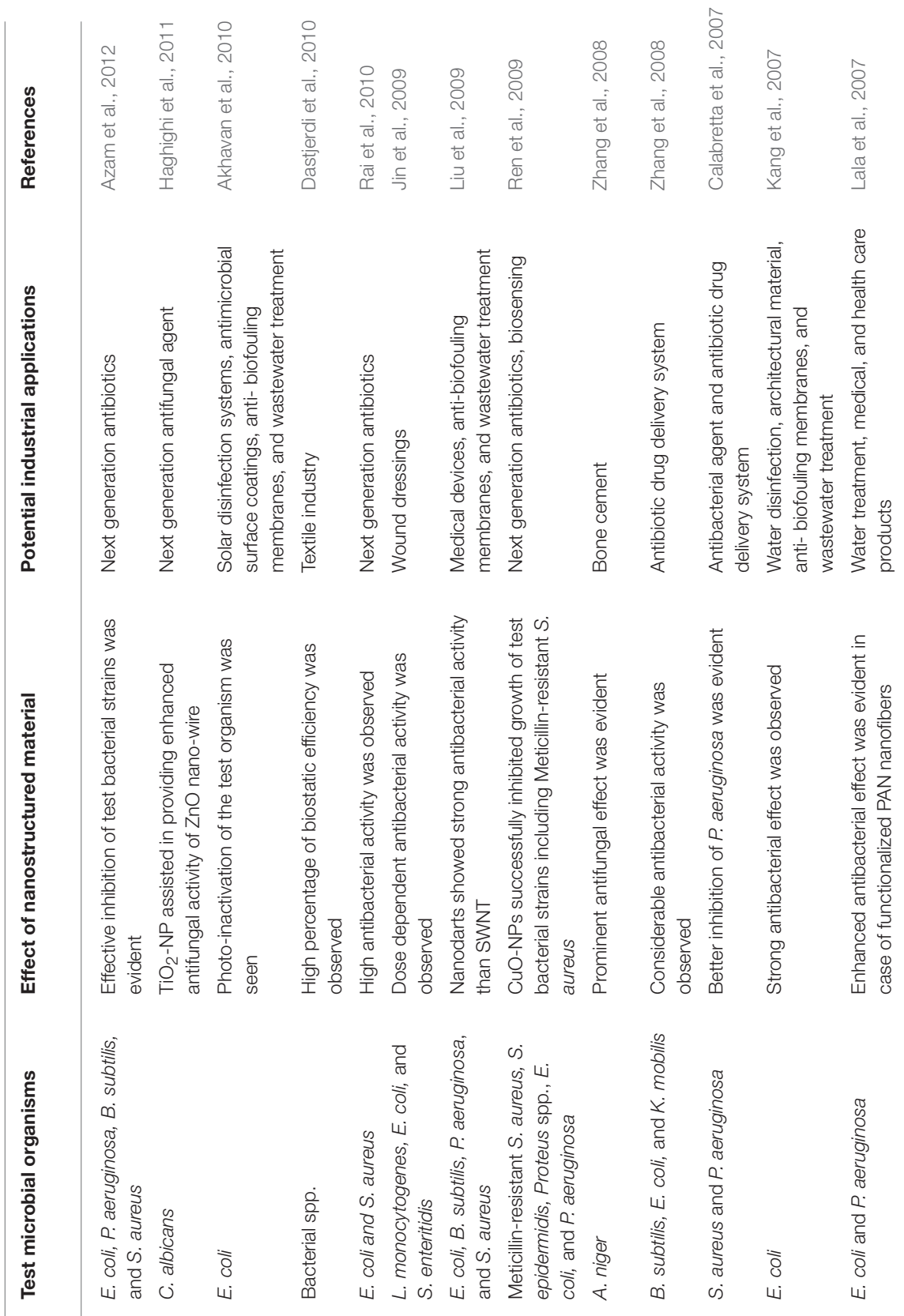

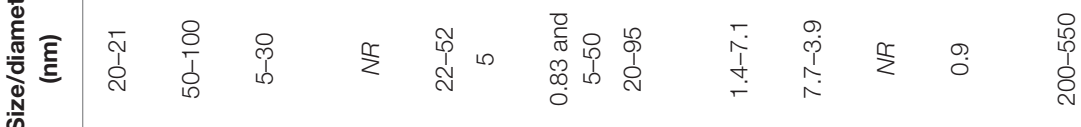

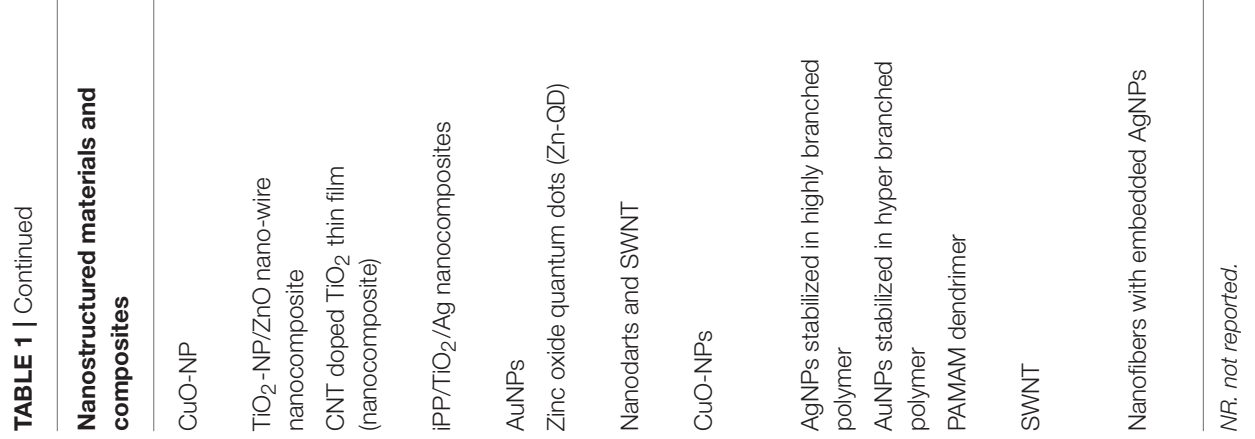


like mechanical durability, crack prevention, biocidal activity, etc. (Lee et al., 2010).

\section{Nanoscale Chitosan (NCH)}

$\mathrm{NCH}$ as an antimicrobial agent has strong potential for potable water disinfection across membranes or water storage tank surface coatings. Owing to its strong, broad-spectrum microbicidal action and innocuous effect on vertebrate animals, $\mathrm{NCH}$ has superseded other disinfectants (Beyth et al., 2015). In recent years, $\mathrm{NCH}$ has found its application not only in healthcare and consumer merchandises but also in agriculture and biomedical products (bone cement and wound dressing material), food packaging, waste water treatment, etc. (Li et al., 2008). The exact mechanism behind its microbial toxicity is not very clear; however, loss of cell wall integrity and consequent alteration in membrane permeability has been reported by Kong et al. (2008). Also, electrostatic attraction amid polycationic chitosan and anionic bacterial cell membrane in some cases is known to neutralize and eventually reverse the bacterial cell surface charge. Loss of semi-permeability of the membrane has been suggested to cause intracellular components leakage and ultimately cell death (Kong et al., 2010; Wassel and Khattab, 2017).

\section{Organic Nanoparticles}

Although a wide range of antimicrobial drugs is available which can efficiently kill or hamper microbial growth, however, their ineffective and inefficient delivery to the target may result in the poor therapeutic index and cause several local and systemic side effects. In last few years, antimicrobial drugs encapsulated in ONP systems have appeared as path-breaking and promising alternatives that have not only increased therapeutic index but also reduced detrimental side effects of the drug (Yang et al., 2009; Nath and Banerjee, 2013). Currently, liposome is one of the most commonly used antimicrobial drug delivery system because it can mimic the microbial cell membrane and easily fuse with the pathogenic microbe (Pushparaj Selvadoss et al., 2017). Owing to the unhindered fusion of microbial cell membrane and liposome, cargos (drugs) easily get released inside the microbial cell and eventually result in its death (Walsh et al., 2001; Yang et al., 2009). Polymeric nanoparticles (PNPs) have also been extensively studied for their potential to deliver wide variety of antimicrobial agents, as they offer numerous unique features like stable structure, narrow size distribution, zeta potential, ability to finely tune drug release profile, etc. (Cheng et al., 2007; $\mathrm{Gu}$ et al., 2008). Like PNPs, dendrimers also possess several exceptional properties, such as large surface area, high in vivo reactivity, and ability to load both polar and non-polar agents, which make them a suitable nano-platform for microbicidal drug delivery (Zhang et al., 2010). Not only this, dendrimer itself can act as a powerful microbicide by using the antimicrobial agent as an elementary unit and the plausible mode of microbial toxicity is accredited to the polycationic structural feature which facilitates its adsorption onto the negatively charged bacterial cell. Once adsorbed, increased membrane permeability is witnessed that ensures entry of more dendrimers inside the cell which later facilitate $\mathrm{K}^{+}$ions leakage and complete loss of bacterial membrane integrity (Chen and Cooper, 2002; Ladd et al., 2017).
The detailed discussion on antimicrobial activity of dendrimers has been described elsewhere (Scorciapino et al., 2017).

\section{LIMITATIONS OF PRESENT WORK AND FUTURE PROSPECTS OF aNSMS}

The exact mechanism behind antimicrobial effects of NSMs still remains unclear. Certain reports recognize ROS generation or development of oxidative stress as a cause of microbicidal effect, while others suggest antimicrobial effect cannot be associated with metabolism regulation (Dakal et al., 2016). Therefore, addressing exact mechanism behind the antimicrobial action of NSMs should be considered in future work. Several microbes present complex cell membrane structure, therefore, the in vitro models cannot completely mimic the in vivo conditions to accurately study the effect of aNSMs in duplicate real systems. Other limitations of the current works include lack of unified standards to compare antimicrobial effects of NSMs in order to ensure their potency as antimicrobial agent. Application of NSMs in waste water treatment has raised serious health concerns due to their aggregation in water. Further, loss of nanoparticles during downstream processing may cause toxicity in human beings and affect different ecosystems, therefore future work should be directed toward developing better technologies for retention of nanomaterials. Also, cost effective NSMs should be looked for the disinfection purpose in order to compete with conventional disinfectants.

\section{CONCLUSIONS}

Owing to their spectacular properties, NSMs in both organic and inorganic forms have engendered several interesting fields in science and technology. Incessant investigation for their application has led to the development of practical productions and commercialization of products in some cases. Considering the current scenario of human health, its comfort, and wellbeing; NSMs have been welcomed open-heartedly by several industries, such as health and personal care industry, textile industry, environmental industry, etc. However, realizing the application of NSMs at large scale in the economic setup is still a long shot. Therefore, future work should be directed toward designing novel, applicable, and inexpensive methodologies for scaled up manufacturing of these NSMs in order to meet the growing human needs.

\section{AUTHOR CONTRIBUTIONS}

$\mathrm{AB}$ and PC: wrote the manuscript; AS: helped in writing; $\mathrm{PK}$, PM, and VB: edited the manuscript. All authors proofread and finalized the manuscript.

\section{ACKNOWLEDGMENTS}

This work is supported by DST Ramanujan Fellowship (SB/S2/RJN-042/2015) awarded to PC by Government of India. AS thanks Dr. U. S. N. Murty, Director NIPER- Guwahati for his support and encouragement. 


\section{REFERENCES}

Abdel-Raouf, N., Al-Enazi, N. M., and Ibraheem, I. B. (2017). Green biosynthesis of gold nanoparticles using Galaxaura elongata and characterization of their antibacterial activity. Arab. J. Chem. 10, S3029-S3039. doi: 10.1016/j.arabjc.2013.11.044

Ahmed, S., Ahmad, M., Swami, B. L., and Ikram, S. (2016). A review on plants extract mediated synthesis of silver nanoparticles for antimicrobial applications: a green expertise. J. Adv. Res. 7, 17-28. doi: 10.1016/ j.jare.2015.02.007

Akhavan, O., Azimirad, R., Safa, S., and Larijani, M. (2010). Visible light photoinduced antibacterial activity of CNT-doped $\mathrm{TiO} 2$ thin films with various CNT contents. J. Mater. Chem. 20, 7386-7392. doi: 10.1039/c0jm00543f

Andrade, F. A. C., De Oliveira Vercik, L. C., Monteiro, F. J., and Da Silva Rigo, E. C. (2016). Preparation, characterization and antibacterial properties of silver nanoparticles-hydroxyapatite composites by a simple and eco-friendly method. Ceram. Int. 42, 2271-2280. doi: 10.1016/j.ceramint.2015.10.021

Anjum, M., Oves, M., Kumar, R., and Barakat, M. (2017). Fabrication of ZnOZnS@polyaniline nanohybrid for enhanced photocatalytic degradation of 2-chlorophenol and microbial contaminants in wastewater. Int. Biodeterior. Biodegrad. 119, 66-77. doi: 10.1016/j.ibiod.2016.10.018

Ansari, S. A., Oves, M., Satar, R., Khan, A., Ahmad, S. I., Jafri, M. A., et al. (2017). Antibacterial activity of iron oxide nanoparticles synthesized by coprecipitation technology against Bacillus cereus and Klebsiella pneumoniae. Polish J. Chem. Tech. 19, 110-115. doi: 10.1515/pjct-2017-0076

Armentano, I., Arciola, C. R., Fortunati, E., Ferrari, D., Mattioli, S., Amoroso, C. F., et al. (2014). The interaction of bacteria with engineered nanostructured polymeric materials: a review. Sci. World J. 2014, 1-18. doi: $10.1155 / 2014 / 410423$

Arokiyaraj, S., Saravanan, M., Prakash, N. U., Arasu, M. V., Vijayakumar, B., and Vincent, S. (2013). Enhanced antibacterial activity of iron oxide magnetic nanoparticles treated with Argemone mexicana L. leaf extract: an in vitro study. Mat. Res. Bull. 48, 3323-3327. doi: 10.1016/j.materresbull.2013.05.059

Azam, A., Ahmed, A. S., Oves, M., Khan, M. S., and Memic, A. (2012). Size-dependent antimicrobial properties of $\mathrm{CuO}$ nanoparticles against grampositive and-negative bacterial strains. Int. J. Nanomed. 7, 3527-3535. doi: $10.2147 / \mathrm{IJN} . \mathrm{S} 29020$

Baranwal, A., Mahato, K., Srivastava, A., Maurya, P. K., and Chandra, P. (2016). Phytofabricated metallic nanoparticles and their clinical applications. RSC Adv. 6, 105996-106010. doi: 10.1039/C6RA23411A

Beyth, N., Houri-Haddad, Y., Domb, A., Khan, W., and Hazan, R. (2015). Alternative antimicrobial approach: nano-antimicrobial materials. Evid. Based Complement. Alternat. Med. 2015, 1-16. doi: 10.1155/2015/246012

Bhushan, B. (2010). Springer Handbook of Nanotechnology. Berlin; Heidelberg: Springer Science \& Business Media.

Bogdanović, U., Lazić, V., Vodnik, V., Budimir, M., Marković, Z., and Dimitrijević, S. (2014). Copper nanoparticles with high antimicrobial activity. Mater. Lett. 128, 75-78. doi: 10.1016/j.matlet.2014.04.106

Calabretta, M. K., Kumar, A., McDermott, A. M., and Cai, C. (2007). Antibacterial activities of poly (amidoamine) dendrimers terminated with amino and poly (ethylene glycol) groups. Biomacromolecules 8, 1807-1811. doi: $10.1021 / \mathrm{bm} 0701088$

Cern, A., Connolly, K. L., Jerse, A. E., and Barenholz, Y. (2018). In vitro susceptibility of Neisseria gonorrhoeae strains to mupirocin. an antibiotic reformulated to parenteral nano-liposomal antibiotic. Antimicrob. Agents Chemother. doi: 10.1128/AAC.02377-17. [Epub ahead of print].

Chen, C. Z., and Cooper, S. L. (2002). Interactions between dendrimer biocides and bacterial membranes. Biomaterials 23, 3359-3368. doi: 10.1016/S0142-9612(02)00036-4

Cheng, J., Teply, B. A., Sherifi, I., Sung, J., Luther, G., Gu, F. X., et al. (2007). Formulation of functionalized PLGA-PEG nanoparticles for in vivo targeted drug delivery. Biomaterials 28, 869-876. doi: 10.1016/ j.biomaterials.2006.09.047

Cui, Y., Zhao, Y., Tian, Y., Zhang, W., Lü, X., and Jiang, X. (2012). The molecular mechanism of action of bactericidal gold nanoparticles on Escherichia coli. Biomaterials 33, 2327-2333. doi: 10.1016/j.biomaterials.2011.11.057

Dakal, T. C., Kumar, A., Majumdar, R. S., and Yadav, V. (2016). Mechanistic basis of antimicrobial actions of silver nanoparticles. Front. Microbiol. 7:1831. doi: $10.3389 /$ fmicb.2016.01831
Das, M. R., Sarma, R. K., Borah, S. C., Kumari, R., Saikia, R., Deshmukh, A. B., et al. (2013). The synthesis of citrate-modified silver nanoparticles in an aqueous suspension of graphene oxide nanosheets and their antibacterial activity. ?Colloids Surf. B 105, 128-136. doi: 10.1016/j.colsurfb.2012.12.033

Dastjerdi, R., Mojtahedi, M., Shoshtari, A., and Khosroshahi, A. (2010). Investigating the production and properties of $\mathrm{Ag} / \mathrm{TiO} 2 / \mathrm{PP}$ antibacterial nanocomposite filament yarns. J. Text. Inst. 101, 204-213. doi: 10.1080/00405000802346388

Dastjerdi, R., and Montazer, M. (2010). A review on the application of inorganic nano-structured materials in the modification of textiles: focus on anti-microbial properties. Colloids Surf. B 79, 5-18. doi: 10.1016/j. colsurfb.2010.03.029

Desselberger, U. (2000). Emerging and re-emerging infectious diseases. J. Infect. 40, 3-15. doi: 10.1053/jinf.1999.0624

Dinali, R., Ebrahiminezhad, A., Manley-Harris, M., Ghasemi, Y., and Berenjian, A. (2017). Iron oxide nanoparticles in modern microbiology and biotechnology. Crit. Rev. Microbiol. 43, 493-507. doi: 10.1080/1040841X.2016.1267708

Dizaj, S. M., Lotfipour, F., Barzegar-Jalali, M., Zarrintan, M. H., and Adibkia, K. (2014). Antimicrobial activity of the metals and metal oxide nanoparticles. Mater. Sci. Eng. C 44, 278-284. doi: 10.1016/j.msec.2014.08.031

Duncan, T. V. (2011). Applications of nanotechnology in food packaging and food safety: barrier materials, antimicrobials and sensors. J. Colloid Interface Sci. 363, 1-24. doi: 10.1016/j.jcis.2011.07.017

El-Nahhal, I. M., Elmanamah, A.A., El Ashgar, N. M., Amara, N., Selmane, M., and Chehimi, M. M. (2017). Stabilization of nano-structured $\mathrm{ZnO}$ particles onto the surface of cotton fibers using different surfactants and their antimicrobial activity. Ultrason. Sonochem. 38, 478-487. doi: 10.1016/j.ultsonch.2017.03.050

Espitia, P. J. P., Soares, N. D. F. F., Dos Reis Coimbra, J. S., De Andrade, N. J., Cruz, R. S., and Medeiros, E. A. A. (2012). Zinc oxide nanoparticles: synthesis, antimicrobial activity and food packaging applications. Food Bioprocess Tech. 5, 1447-1464. doi: 10.1007/s11947-012-0797-6

Gao, W., Vecchio, D., Li, J., Zhu, J., Zhang, Q., Fu, V., et al. (2014). Hydrogel containing nanoparticle-stabilized liposomes for topical antimicrobial delivery. ACS Nano 8, 2900-2907. doi: 10.1021/nn500110a

Ghosh, S., Patil, S., Ahire, M., Kitture, R., Kale, S., Pardesi, K., et al. (2012). Synthesis of silver nanoparticles using Dioscorea bulbifera tuber extract and evaluation of its synergistic potential in combination with antimicrobial agents. Int. J. Nanomed. 7, 483-496. doi: 10.2147/IJN.S24793

Grande, C. D., Mangadlao, J., Fan, J., De Leon, A., Delgado-Ospina, J., Rojas, J. G., et al. (2017). "Chitosan cross-linked graphene oxide nanocomposite films with antimicrobial activity for application in food industry," in Macromolecular Symposia (Weinheim: Wiley Online Library).

Gu, F., Zhang, L., Teply, B. A., Mann, N., Wang, A., Radovic-Moreno, A. F., et al. (2008). Precise engineering of targeted nanoparticles by using self-assembled biointegrated block copolymers. Proc. Natl. Acad. Sci. U.S.A. 105, 2586-2591. doi: 10.1073/pnas.0711714105

Gunalan, S., Sivaraj, R., and Rajendran, V. (2012). Green synthesized ZnO nanoparticles against bacterial and fungal pathogens. Prog. Nat. Sci. Mater. Int. 22, 693-700. doi: 10.1016/j.pnsc.2012.11.015

Habiba, K., Bracho-Rincon, D. P., Gonzalez-Feliciano, J. A., Villalobos-Santos, J. C., Makarov, V. I., Ortiz, D., et al. (2015). Synergistic antibacterial activity of PEGylated silver-graphene quantum dots nanocomposites. Appl. Mater. Today 1, 80-87. doi: 10.1016/j.apmt.2015.10.001

Haghighi, N., Abdi, Y., and Haghighi, F. (2011). Light-induced antifungal activity of TiO 2 nanoparticles/ZnO nanowires. Appl. Surf. Sci. 257, 10096-10100. doi: 10.1016/j.apsusc.2011.06.145

Huang, Z., Zheng, X., Yan, D., Yin, G., Liao, X., Kang, Y., et al. (2008). Toxicological effect of $\mathrm{ZnO}$ nanoparticles based on bacteria. Langmuir 24, 4140-4144. doi: 10.1021/la7035949

Jayaseelan, C., Ramkumar, R., Rahuman, A. A., and Perumal, P. (2013). Green synthesis of gold nanoparticles using seed aqueous extract of Abelmoschus esculentus and its antifungal activity. Ind. Crops Prod. 45, 423-429. doi: 10.1016/j.indcrop.2012.12.019

Jilani, A., Othman, M. H. D., Ansari, M. O., Oves, M., Alshahrie, A., Khan, I. U., et al. (2018). A simple route to layer-by-layer assembled few layered graphene oxide nanosheets: optical, dielectric and antibacterial aspects. J. Mol. Liq. doi: 10.1016/j.molliq.2018.01.042. [Epub ahead of print].

Jin, T., Sun, D., Su, J. Y., Zhang, H., and Sue, H. J. (2009). Antimicrobial efficacy of zinc oxide quantum dots against Listeria monocytogenes, 
Salmonella enteritidis, and Escherichia coli O157: H7. J. Food Sci. 74, 46-52. doi: 10.1111/j.1750-3841.2008.01013.x

Kang, S., Pinault, M., Pfefferle, L. D., and Elimelech, M. (2007). Singlewalled carbon nanotubes exhibit strong antimicrobial activity. Langmuir 23, 8670-8673. doi: 10.1021/la701067r

Khan, A. A., Khan, A., Rahman, M. M., Asiri, A. M., and Oves, M. (2017). Sensor development of 1, 2 dichlorobenzene based on polypyrole/Cu-doped $\mathrm{ZnO}$ (PPY/CZO) nanocomposite embedded silver electrode and their antimicrobial studies. Int. J. Biol. Macromol. 98, 256-267. doi: 10.1016/j.ijbiomac.2017.02.005

Khatoon, U. T., Rao, G. N., Mohan, K. M., Ramanaviciene, A., and Ramanavicius, A. (2017). Antibacterial and antifungal activity of silver nanospheres synthesized by tri-sodium citrate assisted chemical approach. Vacuum 146, 259-265. doi: 10.1016/j.vacuum.2017.10.003

Khot, L. R., Sankaran, S., Maja, J. M., Ehsani, R., and Schuster, E. W. (2012). Applications of nanomaterials in agricultural production and crop protection: a review. Crop Prot. 35, 64-70. doi: 10.1016/j.cropro.2012.01.007

Kong, M., Chen, X. G., Liu, C. S., Liu, C. G., Meng, X. H., and Yu, L. J. (2008). Antibacterial mechanism of chitosan microspheres in a solid dispersing system against E. coli. Colloids Surf. B 65, 197-202. doi: 10.1016/j.colsurfb.2008.04.003

Kong, M., Chen, X. G., Xing, K., and Park, H. J. (2010). Antimicrobial properties of chitosan and mode of action: a state of the art review. Int. J. Food Microbiol. 144, 51-63. doi: 10.1016/j.ijfoodmicro.2010.09.012

Kumar, R., Oves, M., Almeelbi, T., Al-Makishah, N. H., and Barakat, M. (2017). Hybrid chitosan/polyaniline-polypyrrole biomaterial for enhanced adsorption and antimicrobial activity. J. Colloid Interface Sci. 490, 488-496. doi: $10.1016 /$ j.jcis.2016.11.082

Ladd, E., Sheikhi, A., Li, N., van de Ven, T. G., and Kakkar, A. (2017). Design and synthesis of dendrimers with facile surface group functionalization, and an evaluation of their bactericidal efficacy. Molecules 22:868. doi: 10.3390/molecules22060868

Lala, N. L., Ramaseshan, R., Bojun, L., Sundarrajan, S., Barhate, R. S., Ying-Jun, L., et al. (2007). Fabrication of nanofibers with antimicrobial functionality used as filters: protection against bacterial contaminants. Biotechnol. Bioeng. 97, 1357-1365. doi: 10.1002/bit.21351

Latif, U., Al-Rubeaan, K., and Saeb, A. T. (2015). A review on antimicrobial chitosan-silver nanocomposites: a roadmap toward pathogen targeted synthesis. Int. J. Polymeric Mater. Polymeric Biomater. 64, 448-458. doi: 10.1080/00914037.2014.958834

Lee, C., Kim, J. Y., Lee, W. I., Nelson, K. L., Yoon, J., and Sedlak, D. L. (2008). Bactericidal effect of zero-valent iron nanoparticles on Escherichia coli. Environ. Sci. Technol. 42, 4927-4933. doi: 10.1021/es800408u

Lee, J., Mahendra, S., and Alvarez, P. J. (2010). Nanomaterials in the construction industry: a review of their applications and environmental health and safety considerations. ACS Nano 4, 3580-3590. doi: 10.1021/nn100866w

Li, C., Wang, X., Chen, F., Zhang, C., Zhi, X., Wang, K., et al. (2013). The antifungal activity of graphene oxide-silver nanocomposites. Biomaterials 34, 3882-3890. doi: 10.1016/j.biomaterials.2013.02.001

Li, Q., Mahendra, S., Lyon, D. Y., Brunet, L., Liga, M. V., Li, D., et al. (2008). Antimicrobial nanomaterials for water disinfection and microbial control: potential applications and implications. Water Res. 42, 4591-4602. doi: 10.1016/j.watres.2008.08.015

Li, S. M., Jia, N., Ma, M. G., Zhang, Z., Liu, Q. H., and Sun, R. C. (2011). Cellulosesilver nanocomposites: microwave-assisted synthesis, characterization, their thermal stability, and antimicrobial property. Carbohydr. Polym. 86, 441-447. doi: 10.1016/j.carbpol.2011.04.060

Liu, S., Wei, L., Hao, L., Fang, N., Chang, M. W., Xu, R., et al. (2009). Sharper and faster "nano darts" kill more bacteria: a study of antibacterial activity of individually dispersed pristine single-walled carbon nanotube. ACS Nano 3, 3891-3902. doi: 10.1021/nn901252r

Liu, S., Zeng, T. H., Hofmann, M., Burcombe, E., Wei, J., Jiang, R., et al. (2011). Antibacterial activity of graphite, graphite oxide, graphene oxide, and reduced graphene oxide: membrane and oxidative stress. ACS Nano 5, 6971-6980. doi: $10.1021 / \mathrm{nn} 202451 \mathrm{x}$

Lyon, D. Y., Adams, L. K., Falkner, J. C., and Alvarezt, P. J. (2006). Antibacterial activity of fullerene water suspensions: effects of preparation method and particle size. Environ. Sci. Technol. 40, 4360-4366. doi: 10.1021/es0603655

Morse, S. S. (2001). "Factors in the emergence of infectious diseases", in Plagues and Politics, ed A. T. Price-Smith (London: Palgrave Macmillan), 8-26.
Murphy, F. A. (1994). New, emerging, and reemerging infectious diseases. $A d v$ Virus Res. 43, 1-52. doi: 10.1016/S0065-3527(08)60046-9

Nath, D., and Banerjee, P. (2013). Green nanotechnology-a new hope for medical biology. Environ. Toxicol. Pharmacol. 36, 997-1014. doi: 10.1016/j.etap.2013.09.002

Ocsoy, I., Temiz, M., Celik, C., Altinsoy, B., Yilmaz, V., and Duman, F. (2017). A green approach for formation of silver nanoparticles on magnetic graphene oxide and highly effective antimicrobial activity and reusability. J. Mol. Liq. 227, 147-152. doi: 10.1016/j.molliq.2016.12.015

Oves, M., Arshad, M., Khan, M. S., Ahmed, A. S., Azam, A., and Ismail, I. M. (2015). Anti-microbial activity of cobalt doped zinc oxide nanoparticles: targeting water borne bacteria. J. Saudi Chem. Soc. 19, 581-588. doi: 10.1016/j.jscs.2015.05.003

Oves, M., Qari, H. A., Felemban, N. M., Khan, M. Z., Rehan, Z. A., and Ismail, I. M. (2016). Marinobacter lipolyticus from Red Sea for lipase production and modulation of silver nanomaterials for anti-candidal activities. IET Nanobiotechnol. 11, 403-410. doi: 10.1049/iet-nbt.2016.0104

Pushparaj Selvadoss, P., Nellore, J., Balaraman Ravindrran, M., Sekar, U., and Tippabathani, J. (2017). Enhancement of antimicrobial activity by liposomal oleic acid-loaded antibiotics for the treatment of multidrug-resistant Pseudomonas aeruginosa. Artif. Cells Nanomed. Biotechnol. 46, 268-273. doi: 10.1080/21691401.2017.1307209

Qayyum, S., Oves, M., and Khan, A. U. (2017). Obliteration of bacterial growth and biofilm through ROS generation by facilely synthesized green silver nanoparticles. PLoS ONE 12:e0181363. doi: 10.1371/journal.pone.0181363

Rai, A., Prabhune, A., and Perry, C. C. (2010). Antibiotic mediated synthesis of gold nanoparticles with potent antimicrobial activity and their application in antimicrobial coatings. J. Mater. Chem. 20, 6789-6798. doi: $10.1039 / \mathrm{c0jm} 00817 \mathrm{f}$

Ren, G., Hu, D., Cheng, E. W., Vargas-Reus, M. A., Reip, P., and Allaker, R. P. (2009). Characterisation of copper oxide nanoparticles for antimicrobial applications. Int. J. Antimicrob. Agents 33, 587-590. doi: 10.1016/j.ijantimicag.2008.12.004

Ristic, B. Z., Milenkovic, M. M., Dakic, I. R., Todorovic-Markovic, B. M., Milosavljevic, M. S., Budimir, M. D., et al. (2014). Photodynamic antibacterial effect of graphene quantum dots. Biomaterials 35, 4428-4435. doi: 10.1016/j.biomaterials.2014.02.014

Scorciapino, M. A., Serra, I., Manzo, G., and Rinaldi, A. C. (2017). Antimicrobial dendrimeric peptides: structure, activity and new therapeutic applications. Int. J. Mol. Sci. 18:542. doi: 10.3390/ijms18030542

Singh, V., Sandeep, K., Kushwaha, H., Powar, S., and Vaish, R. (2018) Photocatalytic, hydrophobic and antimicrobial characteristics of $\mathrm{ZnO}$ nano needle embedded cement composites. Constr. Build. Mater. 158, 285-294. doi: 10.1016/j.conbuildmat.2017.10.035

Usman, M. S., El Zowalaty, M. E., Shameli, K., Zainuddin, N., Salama, M., and Ibrahim, N. A. (2013). Synthesis, characterization, and antimicrobial properties of copper nanoparticles. Int. J. Nanomed. 8, 4467-4479. doi: $10.2147 /$ IJN.S50837

Walsh, T. J., Goodman, J. L., Pappas, P., Bekersky, I., Buell, D. N., Roden, M., et al. (2001). Safety, tolerance, and pharmacokinetics of high-dose liposomal amphotericin b (AmBisome) in patients infected with Aspergillus species and other filamentous fungi: maximum tolerated dose study. Antimicrob. Agents Chemother. 45, 3487-3496. doi: 10.1128/AAC.45.12.3487-3496.2001

Wassel, M. O., and Khattab, M. A. (2017). Antibacterial activity against Streptococcus mutans and inhibition of bacterial induced enamel demineralization of propolis, miswak, and chitosan nanoparticles based dental varnishes. J. Adv. Res. 8, 387-392. doi: 10.1016/j.jare.2017.05.006

Weir, A., Westerhoff, P., Fabricius, L., Hristovski, K., and von Goetz, N. (2012). Titanium dioxide nanoparticles in food and personal care products. Environ. Sci. Technol. 46, 2242-2250. doi: 10.1021/es204168d

Wijnhoven, S., Oomen, A., Sips, A., Bourgeois, F., Te Dorsthorst, G., Kooi, M., et al. (2010). Development of an inventory for consumer products containing nanomaterials. Available onlin at: http://ec.europa.eu/environment/chemicals/ nanotech/pdf/study_inventory.pdf

Yang, D., Pornpattananangkul, D., Nakatsuji, T., Chan, M., Carson, D., Huang, C. M., et al. (2009). The antimicrobial activity of liposomal lauric acids against Propionibacterium acnes. Biomaterials 30, 6035-6040. doi: $10.1016 /$ j.biomaterials.2009.07.033 
Zhang, L., Pornpattananangku, D., Hu, C. M., and Huang, C. M. (2010). Development of nanoparticles for antimicrobial drug delivery. Curr. Med. Chem. 17, 585-594. doi: 10.2174/092986710790416290

Zhang, Y., Peng, H., Huang, W., Zhou, Y., and Yan, D. (2008). Facile preparation and characterization of highly antimicrobial colloid $\mathrm{Ag}$ or Au nanoparticles. J. Colloid Interface Sci. 325, 371-376. doi: 10.1016/j.jcis.2008.05.063

Zheng, K., Setyawati, M. I., Leong, D. T., and Xie, J. (2017). Antimicrobial gold nanoclusters. ACS Nano 11, 6904-6910. doi: 10.1021/acsnano.7b02035

Zhu, J., Wang, J., Hou, J., Zhang, Y., Liu, J., and Van Der Bruggen, B. (2017). Graphene-based antimicrobial polymeric membranes: a review. J. Mater. Chem. A 5, 6776-6793. doi: 10.1039/C7TA00009J
Conflict of Interest Statement: The authors declare that the research was conducted in the absence of any commercial or financial relationships that could be construed as a potential conflict of interest.

Copyright (c) 2018 Baranwal, Srivastava, Kumar, Bajpai, Maurya and Chandra. This is an open-access article distributed under the terms of the Creative Commons Attribution License (CC BY). The use, distribution or reproduction in other forums is permitted, provided the original author(s) and the copyright owner are credited and that the original publication in this journal is cited, in accordance with accepted academic practice. No use, distribution or reproduction is permitted which does not comply with these terms. 